\title{
GESTAÇÃO DE ALTO RISCO E BAIXO PESO AO NASCER EM GOIÂNIA
}

\author{
GESTATION OF HIGH RISK AND LOW WEIGHT AT BIRTH IN GOIÂNIA \\ GESTACIÓN DE ALTO RIESGO Y BAJO PESO AL NACER EN GOIÂNIA
}

\section{Cleusa Alves Martins $^{1}$
Leilinéia Pereira Ramos de Rezende $^{2}$ Dayane Cristina Silva Vinhas ${ }^{3}$}

\begin{abstract}
RESUMO: Realizou-se estudo a cerca da Doença Hipertensiva Específica da Gestação (DHEG) e RecémNascidos de Baixo Peso (RNBP), com os objetivos de verificar a incidência de RNBP em mães com DHEG e apresentar alguns dados epidemiológicos. Os dados foram coletados através de um roteiro. Pesquisamos 239 prontuários de gestantes com DHEG e seus respectivos recém-nascidos, no período de janeiro-1998 a dezembro2002, em um hospital público de Goiânia. Constatamos que $69,70 \%$ das mães tiveram filhos com peso menor que $2500 \mathrm{~g}$, levando-nos a concluir que a DHEG influencia na incidência de RNBP, visto que em menos de $50 \%$ dos casos, houve o nascimento pré-termos. A maioria das mães era primigestas. Mais de $50 \%$ destas fizeram prénatal, porém, apenas 39,70\% realizaram mais de seis consultas. Em 82,85\% dos casos, a via de parto foi cesariana.
\end{abstract}

Palavras chaves: Pré-eclâmpsia; Eclampsia; Recém-nascido de Baixo Peso.

SUMMARY: It happened a study of the Specific Hypertensive of Gestation Disease (SHGD) and Low Weight of New Born (LWNB) with the objectives to verify the incidence of LWNB in mothers with SHGD and to present some epidemic data. The data was collected through a trial. From January-1998 through December-2002 in a public hospital of Goiânia, we researched 239 files of pregnant women with DHEG and their respective new born. We verified that $69,70 \%$ of the mothers had children with smaller weight than $2500 \mathrm{~g}$, leading us to conclude that DHEG influences in the incidence of RNBP, because in less than $50 \%$ of the cases, there was a birth of pre-term. Most of the mothers were pregnant for the first time. More than $50 \%$ of them made prenatal, however, only $39,70 \%$ accomplished more than six consultations. In $82,85 \%$ of the cases, the childbirth was via cesarean operation.

Keywords: Pre-eclampsia; Eclampsia; Infant Low birth Weight.

RESUMEN: Se realizó un estudio acerca de la Enfermedad Hipertensiva Específica de la Gestación (DEG) y recién nacidos de bajo peso (RNBP), con los objetivos de verificar la incidencia de RNBP en madres con DEG y presentar algunos datos epidemiológicos. Los datos fueron colectados a través de un guión. Investigamos 239 historias clínicas de embarazadas con DEG y sus respectivos recién nacidos, en el período de Enero- 1998 a Diciembre- 2002, en un hospital público de Goiania. Constatamos que $69,70 \%$ de las madres tuvieron hijos con peso menor que $2500 \mathrm{~g}$, llevándonos a concluir que la DEG influencia en la incidencia de RNBP, visto que en menos de $50 \%$ de los casos hubo el nacimiento pre-términos. La mayoría de las madres tenían la primera gestación (primigestas). Más de $50 \%$ de éstas hicieron prenatal, pero sólo $39,70 \%$ realizaron más de seis consultas. En 82,85\% de los casos, la vía del parto fue cesárea.

Términos claves: Preeclampsia; Eclampsia; Recién Nacido de Bajo Peso.

\section{INTRODUÇÃO}

Toxemia gravídica, termo utilizado há muitas décadas, inapropriadamente, para definir esta doença, pois se pensava que havia interferência de agentes tóxicos na circulação sangüínea causando os distúrbios hipertensivos, consagrando-se assim, universalmente pelo seu uso corrente na literatura. Em nosso estudo, utilizaremos o termo Doença Hipertensiva Específica da Gestação (DHEG), por melhor expressar as características desta entidade.

Sabemos que, na gestação mesmo havendo alterações anatômicas, endócrinas, hemodinâmicas e imunológicas importantes, o organismo feminino se mantém em equilíbrio dinâmico por mecanismos compensatórios. Contudo, o limite entre a normalidade e a doença é extremamente tênue e o desequilíbrio representa risco elevado de morbimortalidade materno-fetal.

A Doença Hipertensiva Específica da Gestação, de acordo com Ministério da Saúde, BRASIL (2000), CINTRA (2001) E VIGGIANO (1989), trata-se de uma patologia obstétrica que surge após a vigésima semana de gestação. Segundo REZENDE (1995), surge após a vigésima quarta semana gestacional, sendo mais freqüente no terceiro trimestre e se estende até o puerpério. Caracteriza-se por apresentar hipertensão arterial, edema e/ou proteinúria, podendo culminar com convulsões e coma. Para o Ministério da Saúde, BRASIL (2000), a Pré-Eclampsia pode ocorrer

\footnotetext{
${ }^{1 *}$ Orientadora, Doutora e Professora adjunta da Faculdade de Enfermagem da Universidade Federal de Goiás- FEN/UFG.

${ }^{2}$ Acadêmica do $5^{\circ}$ ano de enfermagem da Universidade Federal de Goiás e bolsista do Programa Especial de Treinamento PET. E-Mail: leilineia@zipmail.com.br.

${ }^{3^{*}}$ Acadêmica do $5^{\circ}$ ano de enfermagem da Universidade Federal de Goiás.
} 
anteriormente a vigésima semana de gravidez, na moléstia trofoblástica gestacional, sendo, predominantemente, uma patologia de primigesta.

CINTRA (2001), afirma que lesões hiperplásticas e obstrutivas das arteríolas teciduais ocorrem uniformemente em pacientes portadoras de hipertensão. E estariam relacionados ao menor afluxo sangüíneo, dependente do espasmo arteriolar generalizado, donde decorre o estado hipoxêmico. Essas alterações anátomo-funcionais levam ao quadro de insuficiência placentária com conseqüente repercussão nas duas funções trofoblásticas: respiratória e nutritiva.

Quando o processo se instala precocemente, a nutrição fetal fica comprometida afetando, severamente, o produto da gestação que nasce com baixo peso para idade gestacional, ou seja, com peso inferior a dois desvios padrão da média, concordando com o Ministério da Saúde, BRASIL M.S (2000), o qual afirma que o peso inferior a $2500 \mathrm{~g}$ pode ser em conseqüência do nascimento prematuro e da qualidade do crescimento fetal intra-uterino.

Nessa linha de pensamento, o tema traz a inquietação de aluna e bolsista de iniciação científica, desenvolvendo atividades práticas na área obstétrica em relação às observações empíricas de grande incidência de recém-natos com baixo peso ao nascer, em mães que apresentavam diagnóstico de Doença Hipertensiva Específica da Gestação (DHEG), e ainda, as conseqüências drásticas que a patologia pode representar na gestação, em dados como: idade gestacional ao nascer, paridade, pré-natal e via de parto.

\section{OBJETIVOS}

$x$ Verificar a incidência de Recém-Nascidos de Baixo Peso em mães com Doença Hipertensiva Específica da Gestação, em Goiânia.

$x$ Apresentar dados epidemiológicos: idade gestacional do recém-nascido, peso fetal ao nascer, gestações anteriores, número de consultas pré-natais e tipo de parto mais comum nestes casos.

\section{METODOLOGIA}

Trata-se de um estudo descritivo, que se utilizou subsídios quantitativos realizada em um hospital público, em Goiânia-Goiás. A população foi constituída de 239 prontuários de pacientes portadoras de DHEG e seus respectivos recém nascidos, no período de janeiro de 1998 a dezembro de 2002, e acatou-se normas da Resolução 196/96, do Conselho Nacional de Saúde. Os dados foram obtidos por meio de um roteiro, atinando-se para questões referentes ao parto, ao recém-nascido e gestações que apresentaram essa patologia.

\section{A DOENÇA HIPERTENSIVA ESPECÍFICA DA GESTAÇÃO}

O quadro clínico da Doença Hipertensiva Específica da Gestação conforme afirma REZENDE (1995), pode apresentar evolução distinta: PréEclampsia $\square$ quando aparece apenas hipertensão, edema e/ou proteinúria. Mas, se ocorre associação de convulsão, essa tríade é dita Eclampsia. No quadro clínico, um ou mais dos sintomas estão presentes:

XPressão arterial: aumento da pressão arterial diastólica a $90 \mathrm{mmHg}$ ou mais, ou aumento da pressão arterial diastólica acima de $140 \mathrm{mmHg}$ do valor conhecido previamente, confirmado após duas medidas com intervalo de no mínimo 4 horas, com a gestante sentada, em repouso.

xProteinúria: presença de $300 \mathrm{mg}$ ou mais de proteínas em urina de 24 horas ou Labistix $1(+) / 4(+)$ ou mais em amostra casual.

$x$ Edema: quando existente, pode ser localizado ou generalizado.

Além destes sintomas, também podem ocorrer oligúria: diurese inferior a $400 \mathrm{ml}$ por dia; cefaléia; dor epigástrica; cianose ou edema pulmonar confirmado; dor no hipocôndrio direito (rotura da cápsula de Glinson); trombocitopenia grave: plaquetas abaixo de 100.000 /mm3; anemia hemolítica microangiopática: hemólise; icterícia e/ou elevação das enzimas hepáticas; e crescimento intra-uterino retardado (CIUR ou RCIU).

Eclampsia é o aparecimento de convulsão em uma paciente com pré-eclampsia. Pode ocorrer na gravidez, parto ou até 10 dias de puerpério. A eminência de Eclampsia é caracterizada clinicamente por sinais de encefalopatia hipertensiva, dor no epigástrio e hipocôndrio direito. Devem ser excluídas a epilepsia e outras doenças convulsivantes.

CINTRA (2001), afirma que a hipertensão induzida ou agravada pela gravidez desenvolve-se com maior freqüência em mulheres expostas ao vilo corial pela primeira vez; expostas à superabundância de vilo corial (mola hidatiforme, gestações múltiplas); que tenham doenças vasculares preexistentes; e que sejam geneticamente predispostas ao desenvolvimento da hipertensão durante a gravidez.

Para esta autora, a hipertensão arterial consta como uma das principais causas de obituário materno, tanto em países desenvolvidos como em países em desenvolvimento.

Deve-se salientar ainda, que a elevada morbidade da doença, pode provocar lesões neurológicas, renais, pulmonares, cardíacas e hepáticas, assim como afetar a morbiletalidade perinatal, óbito fetal intra-útero, prematuridade e baixo peso ao nascimento. A insuficiência vascular úteroplacentéria é responsável por aumentar as taxas de retardo no crescimento intra-uterino com baixo peso ao nascer e também óbito fetal. $\mathrm{O}$ descolamento 
prematuro da placenta, em aproximadamente $50 \%$ dos casos é decorrente da DHEG e outras complicações associadas à prematuridade, contribuindo para a mortalidade neonatal.

$\mathrm{Na}$ gestação a vascularização uterina, segundo CINTRA (2001), sofre grandes alterações para fornecer suprimento sangüíneo adequado ao útero em crescimento e ao produto gestacional, as artérias espiraladas se dilatam, atingindo até trinta vezes seu diâmetro pré-gestacional.

Entre a décima e a décima sexta semana de gestação ocorre a primeira onda de invasão trofoblástica, com ocupação da camada muscular e do endométrio da porção decidual das artérias espiraladas.

A segunda onda de invasão entre décima sexta e a vigésima segunda semana se estende às porções miometriais das artérias espiraladas. Estes vasos tornam-se dilatados, incapazes de sofrer contração e apresentam tecido trofoblástico em contato direto com o sangue materno.

Para CINTRA (2001), gestantes com distúrbios hipertensivos na gravidez, não apresentam a segunda onda de invasão trofoblástica no parênquima uterino. O tecido trofoblástico fica superficial e não avança além da porção decidual das artérias espiraladas. $\mathrm{O}$ diâmetro externo final destes vasos no miométrio é menor que a metade dos vasos similares em gestantes normais.

Não ocorrendo a invasão trofoblástica dos vasos uterinos, que estão uniformemente contraídos, haverá hipoperfusão do trofoblasto. Acredita-se que ocorra a produção de um agente, pelo tecido trofoblástico em sofrimento, que seja citotóxico e juntamente com outros mecanismos, cause dano ao endotélio.

A cliente com distúrbio hipertensivo na gravidez, segundo CINTRA (2001) e REZENDE (1995), não apresenta aumento do volume plasmático sendo que este é pequeno ou inexistente. Há elevação do hematócrito. $\mathrm{O}$ débito cardíaco poderá estar normal, aumentado ou diminuído, dependendo da gravidade, duração da doença e terapêutica utilizada. A pressão arterial é elevada, assim como a resistência vascular periférica, com diminuição de perfusão em vários órgãos. Há um estado hemodinâmico de baixo volume, alta pressão e alta resistência.

Mesmo em casos de doenças sistêmicas com comprometimento vascular, como vasculites ou aterosclerose materna, mola hidatiforme, diabetes e lúpus eritematoso sistêmico, o resultado final é a nãoocorrência da segunda onda de invasão trofoblástica, com o mesmo comprometimento de hipoperfusão dos tecidos trofoblásticos. A razão do fenômeno da nãoinvasão trofoblástica, segundo esses autores, é desconhecida, mas acredita-se na existência de mecanismos bioquímicos, imunológicos e genéticos envolvidos neste processo, que não foram comprovadamente definidos.
Uma das graves complicações de distúrbios hipertensivos na gravidez é a síndrome HELLP, caracterizada por hemólise, elevação de enzimas hepáticas e plaquetopenia. O fígado gorduroso da gravidez, também é considerado complicação,e se trata de uma patologia grave, de etiologia indeterminada. Pacientes com estas patologias devem ter acompanhamento rigoroso, com internação e cuidados em terapia intensiva, afirma CINTRA (2001).

Geralmente, entre outros, os distúrbios hipertensivos na gravidez são graves, e acarretam um aumento na incidência de parto cesárea, potencializando as complicações. A doença apresenta um elevado índice de morbiletalidade materna e perinatal, que exige uma intervenção rápida e segura para o concepto.

Pacientes com gravidez em curso, segundo CINTRA (2001), devem ficar em decúbito dorsal, com a cabeceira do leito em semi-Fowler. Em casos graves, repouso em decúbito lateral esquerdo, o maior tempo possível, ou decúbito elevado a $45^{\circ}$, se a paciente estiver consciente e orientada. A gestante acima de vinte semanas pode ter $20 \%$ a $30 \%$ de redução do débito cardíaco em posição supina, por este motivo é necessário observar o posicionamento.

Deve ser feito o controle rigoroso da freqüência respiratória em pacientes sem assistência ventilatória, e a oxigenação com ventilação mecânica e sedação, bem como podem ser necessários monitorização cardíaca e controle de níveis pressóricos (inclusive com métodos invasivos, em casos mais graves).

Outros procedimentos que podem ser necessários: Controle diário de proteinúria, por urina tipo I ou reação colorimétrica urinária com fitas especiais, sondagem vesical de demora com controle rigoroso de diurese e balanço hídrico, avaliação constante da função renal, eletrólitos, hematimetria, pesquisa de dimorfismo eritrocitário, plaquetas, coagulograma completo, TGO/TGP, LDH, bilirrubinas, glicemia, gasometria arterial no mínimo uma vez ao dia, com correção dos distúrbios, com acidemia, insuficiência renal, alterações de coagulação, hemorragias.

A monitorização fetal deve ser realizada após a estabilização da paciente. A enfermagem deve manter-se atenta aos sintomas: dor epigástrica ou em hipocôndrio direito, náuseas e/ou vômitos e, na prevenção de crises convulsivas dentre outros procedimentos da conduta clínica na eclampsia e está indicado, sob prescrição médica, o sulfato de magnésio $(\mathrm{SO} 4 \mathrm{Mg})$, e no caso de recorrências subentrantes, opta-se pela fenil-hidantoína. Entretanto, na pré-eclampsia, convém lembrar a relação risco/benefício do uso de medicamentos com potenciais efeitos teratogênicos ou outros efeitos colaterais, a administração deve ser feita com rigoroso critério, recomenda-se o Ministério da Saúde (BRASIL; 2000). 
Já, na pré-eclâmpsia leve, a conduta consiste em tratamento ambulatorial, repouso, dieta normossódica e controle do ganho de peso excessivo. A via de parto depende da indicação obstétrica (não ultrapassando 40 semanas de gestação),

Portanto, um importante meio profilático para se reduzir a incidência de Doença Hipertensiva Específica da Gestação é a assistência adequada ao pré-natal, realizada por enfermeiro, com consultas periódicas e intervalos habituais - no mínimo seis, sendo duas consultas médicas, (no entanto, em presença de qualquer sinal ou sintoma de alteração de risco, a gestante deve ser encaminhada ao médico).

\section{RECÉM-NASCIDOS DE BAIXO PESO}

Segundo dados do Ministério da Saúde (BRASIL; 2000a), a freqüência dos recém- nascidos de baixo peso é estimada entre 10 e $15 \%$, de todas as gestações. No entanto para a problemática do retardo de crescimento fetal ou redução do crescimento intrauterino e das complicações associadas ao nascimento, respectivamente, não existe, ainda, tratamento específico. O estabelecimento da conduta fica na dependência da idade gestacional, das condições de vitalidade fetal, da evolução clínica e do fator causal. Propõem-se medidas como repouso materno e a correção dos fatores causais identificados.

São considerados recém nascidos de baixo peso quando o peso do recém-nato for menor que $2500 \mathrm{~g}$. A qualidade do crescimento fetal depende da interação do organismo do feto com o de sua mãe, e o suprimento por fatores maternos e placentários (BRASIL, 2000a).

RAMOS (1986), avalia clinicamente o crescimento fetal, determinando-se a altura do fundo do útero através do exame bimanual do abdome gravídico. Além disso, as medidas de ultra-sonografia do diâmetro biparietal, do comprimento do fêmur e do perímetro abdominal fetais, são também empregadas para se estimar o crescimento fetal.

A combinação dessas medições prediz com exatidão o peso fetal. Os desvios da curva de crescimento serão relacionados a condições de alto risco. O desenlace do feto ou recém-nascido com retardo do crescimento dependem da redução do crescimento intra-uterino e das complicações associadas ao nascimento.
Para RAMOS (1986), dentre outros, os fatores influentes no retardo de crescimento fetal são as Causas fetais (rubéola congênita, síndromes de nanismo primordial, anormalidades cromossômicas, síndromes de má formação congênita, produção fetal reduzida de insulina e de fator de crescimento semelhante à insulina I $\mathrm{FCl}-\mathrm{I}$ ); Causas placentárias (tumores placentários, descolamento prematuro crônico da placenta, transfusões intergemelares, insuficiência placentária, dentre outras); e causas maternas (doenças vasculares periféricas que reduzem 0 afluxo sanguíneo útero-placentário, hipertensão arterial crônica, vasculopatia diabética, entre outros). A pré-eclampsia e eclampsia constituem risco para o nascimento de recém-nascidos de baixo peso. Vale dizer, que ainda não há provas de que a redução do fluxo sanguíneo útero-placentário seja a causa de retardo de crescimento no feto humano, embora se saiba, várias causas que reduzem esse fluxo estão associadas a recém nascidos pequenos para idade gestacional.

Um importante dado sobre a relação pressão arterial materna/peso fetal foi desenvolvido por NAYE e cols (1973), demonstraram que pressão diastólica máxima obtida durante a gravidez, aumenta quando aumentam o peso pré-gravídico e o ganho líquido de peso na gravidez, ou seja, o peso total ganho pela mãe menos o do feto e o da placenta.

Os dados sugerem que muitas modificações do crescimento fetal atribuídos à nutrição oferecida pela mãe sejam, na realidade, mediados pela pressão arterial e pela perfusão uterino-placentária.

$\mathrm{Na}$ compreensão de que a gravidez não é doença, mas ocasionalmente poderão ocorrer intercorrências que afetam drasticamente a mãe e ao concepto, o estudo busca avançar na realidade epidemiológica local considerando a relevância aos fatores mencionados e outros a serem identificados como de risco, para implementação de ações normalizadas de controle pré-natal, que configure um padrão de qualidade, aplicado à população de mulheres no período grávido-puerperal.

\section{RESULTADOS}

Os resultados foram coletados e em seguida apresentados em números absolutos conforme demonstrado nas tabelas a seguir:

Tabela 1 - Distribuição segundo a condição de nascimento dos RN

\begin{tabular}{lll}
\hline Recém-nascidos & N. & $\%$ \\
\hline Vivos & 198 & 82,84 \\
Mortos & 26 & 10,87 \\
Sem informação & 15 & 6,29 \\
\hline Total & 239 & 100 \\
\hline
\end{tabular}

Conforme a tabela acima, percebemos que a grande maioria $(82,84 \%)$ dos neonatos nasceu com vida, sendo que os mortos (incluindo natimortos), dentro da população estudada, foram $10,87 \%$. 
Tabela 2 - Distribuição de peso dos recém-nascidos vivos

\begin{tabular}{lll}
\hline Peso & $\mathrm{N}$. & $\%$ \\
\hline Menor que 2500 g & 138 & 69,70 \\
Maior ou igual a 2500 g & 60 & 30,30 \\
\hline Total & 198 & 100 \\
\hline
\end{tabular}

A tabela 2 mostra que no hospital pesquisado, 138 crianças nasceram com peso menor que $2500 \mathrm{~g}$. Isso corresponde a $69,70 \%$ do total de recém-nascidos vivos, corroborando com REZENDE (1995), que afirma que o baixo peso ao nascer pode decorrer da DHEG.

Tabela 3 - Distribuição segundo as idades gestacionais (IG)

\begin{tabular}{lll}
\hline IG & N. & $\%$ \\
\hline Antes de 37 semanas & 73 & 30,54 \\
De 37 a 41 semanas & 148 & 61,92 \\
Acima de 42 semanas & 16 & 6,69 \\
Sem Informação & 2 & 0,85 \\
\hline Total & 239 & 100 \\
\hline
\end{tabular}

A tabela 3 mostra que dos 239 casos de DHEG, $61,92 \%$ das crianças nasceram a termo. $E$, observando a tabela 2, os dados revelam que o baixo peso ao nascer não estava atrelado a idade gestacional, pois $69.70 \%$ dos fetos que nasceram com peso baixo para a idade gestacional o parto ocorreu entre 37 e 42 semanas).

Isso leva-nos a afirmar que a idade gestacional não influenciou no resultado, uma vez que os resultados constatados na tabela 2 apresentam $31 \%$ do total de recém-nascidos.

Contudo, no estudo, verificou-se alta incidência

Tabela 4 - Distribuição segundo a paridade de recém-nascidos que apresentaram baixo peso para a idade gestacional, justificando a relação doença hipertensiva específica da gestação como um dos fatores preponderantes do baixo peso fetal ao nascer. Pois, de acordo com REZENDE e MONTENEGRO (1995), e NEME(1995), as alterações morfológicas funcionais no organismo da gestante portadora de perturbações circulatórias atingem, dentre outros órgãos, a circulação útero-placentária em cerca de 40 a $60 \%$ dos casos, com incidência de grandes enfartes placentários.

\begin{tabular}{lll}
\hline Paridade & N. & $\%$ \\
\hline Primigestas & 135 & 56,48 \\
Secundíparas & 44 & 18,41 \\
Multíparas & 52 & 21,76 \\
Sem Informação & 8 & 3,35 \\
\hline Total & 239 & 100 \\
\hline
\end{tabular}

A tabela 4 mostra que em $56,48 \%$ dos casos, as mães eram primigestas, concordando com CINTRA (2001), que afirma que a DHEG é predominantemente uma patologia de primigestas, pois menos da metade soma-se as puérperas secundíparas e multíparas.

Tabela 5 - Distribuição segundo a assistência pré-natal

\begin{tabular}{lll}
\hline Pré - natal & N. & $\%$ \\
\hline Sim & 136 & 56,90 \\
Não & 71 & 29,70 \\
Sem Informação & 32 & 13,40 \\
\hline Total & 239 & 100 \\
\hline
\end{tabular}

Conforme a tabela acima, mais de $50 \%$ das

mães fez pré-natal, embora $13,40 \%$ dos prontuários não havia informação acerca da assistência pré-natal, observa-se, contudo, um número bastante significativo 
MARTINS, C.A.; REZENDE, L.P.R.; VINHAS, D.C.S. - Gestação de alto risco e baixo peso ao nascer em Goiânia. Revista 54 Eletrônica de Enfermagem, v. 5 n. 1 p. 49 - 55, 2003. Disponível em http:/www.fen.ufg.br/Revista.

de gestantes que não realizaram pré-natal, ou seja, em torno de $30 \%$ das mulheres grávidas, constituindo assim, um dos fatores determinantes no controle e prevenção da DHEG.

Tabela 6 - Distribuição segundo o número de consultas pré-natal

\begin{tabular}{lll}
\hline Número de consultas & N. & $\%$ \\
\hline Mais que seis & 54 & 39,70 \\
Menos que seis & 82 & 60,30 \\
\hline Total & 136 & 100 \\
\hline
\end{tabular}

Observa-se, na tabela 6 que apenas 39,70\% das mães, realizaram pré-natal efetivamente, ou seja, com mais de seis consultas. Entretanto, é importante estar alerta para os dados da tabela 5 onde apenas $(56,90 \%)$ das mães fizeram pré-natal, independente do número de consultas. Segundo MARTINS (2001), estes dados freqüentemente além de outras causas contribuem para o agravamento do problema, uma vez que os indicadores de mortalidade registram claramente a importância de medidas de assistência às gestantes e recém-nascidos.

Tabela 7 - Distribuição segundo a via de parto

\begin{tabular}{lll}
\hline Via de parto & N. & $\%$ \\
\hline Operatório & 198 & 82,85 \\
Normal & 30 & 12,55 \\
Sem Informação & 11 & 4,60 \\
\hline Total & 239 & 100 \\
\hline
\end{tabular}

Observa-se na tabela acima, que a via de parto predominante foi a cesariana, concordando com GRASSIOTO (1984). Entretanto vale a pena lembrar que no Estado de Goiás, segundo MARTINS (2001) dentre as causas obstétricas diretas que lideram os altos índices de morte materna, destacam-se a infecção e a toxemia, coeficientes que encontram-se associados à má qualidade da assistência pré-natal.

\section{CONSIDERAÇÕES FINAIS}

A análise dos resultados evidenciou que $o$ número de crianças que nasceu com baixo peso para idade gestacional foi dominante. O número de prétermos foi de $30,54 \%$, reforçando que a doença hipertensiva específica da gestação realmente influencia na incidência de recém-nascidos de baixo peso, uma vez que, a idade gestacional não influenciou no resultado, visto que $61,92 \%$ dos conceptos nasceram a termo, ou seja, com idade gestacional adequada (entre 37 e 41 semanas) e em $6,69 \%$ dos casos, o parto ocorreu com 42 semanas.

A maior parte dos prontuários, ou seja, $60,30 \%$ registra que as mães eram primigestas e não realizaram o pré-natal adequadamente pois apenas $39,70 \%$ das clientes fizeram mais de seis consultas.

Os achados, também mostram que a via de parto predominante foi a cesariana, evitando assim o risco de morte para a mãe e o neonato, pois o agravamento da patologia para eclampsia grave, (por exemplo a ocorrência da Síndrome Hellp), embora pouco comum, tem grandes chances de ocorrer. Assim, o mais importante é intervir com medidas gerais das quais se inclui o parto cirúrgico.

Com base em tudo isso, vemos que as questões da DHEG devem estar atreladas à humanização da assistência à mulher no período gravídico-puerperal, prática que fortalece as condutas com enfoque na prevenção, sintonizadas em novos pressupostos que encarem a saúde no contexto político-econômico, cultural e histórico, no qual a gravidez não é um processo de doença e as intervenções dos profissionais devem adotar condutas que tragam bem estar e garantam a segurança para a mulher e para o seu filho, restringindo abordagens tradicionais desnecessárias e muitas vezes potencialmente iatrogênicas.

\section{REFERÊNCIAS BIBLIOGRÁFICAS}

BRASIL, Ministério da Saúde. Secretaria de Políticas de Saúde. Gestação de alto risco. Manual técnico. 3. ed. Brasília: Ministério da Saúde, 2000. Urgências e emergências maternas. Manual técnico. 2 ed. Brasília: Ministério da Saúde, 2000a. CINTRA, E. A; NISHIDE, V.W; NUNES, W.A. A assistência de enfermagem ao paciente gravemente enfermo. São Paulo: Atheneu, 2001. 
GRASSIOTO, O.R. et all. A influencia da hipertensão arterial durante a gravidez sobre o peso do recémnascido Jornal Brasileiro de Ginecologia n. 94, 1984.

MARTINS, C. A. O Programa de assistência Integral à saúde (PAISM) em Goiânia: a (des) institucionalização da consulta de enfermagem no pré-natal. 2001, 200p. Tese (doutorado) - escola de Enfermagem Anna Nery (EEAN), Universidade Federal do Rio de Janeiro (UFRJ), Rio de Janeiro.

NAYE, R.L.; BLANC, W. E PAUL, C. Effects of material nutrition on the human fetus. Pediatrics 52: 4941973.

RAMOS, J.L.A. e LEONE, C.R. O recém-nascido de baixo peso. Monografias médicas, série "pediatria", vol. XXVII. São Paulo: Sarvier, 1986.

REZENDE, J. e MONTENEGRO, C.A.B. Obstetrícia fundamental. 7. ed. Rio de Janeiro: Guanabara Koogan, 1995, p. 241-248.

VIGGIANO, Maurício Guilherme C. Condutas em obstetrícia 3. ed. São Paulo/Rio de Janeiro: Atheneu, 1989, p. 179 - 197 e 231 - 252.

Texto original recebido em: 08/04/2003;

Publicação aprovada em: 27/06/2003. 